\title{
Estrogen induces cardioprotection in male C57BL/6J mice after acute myocardial infarction via decreased activity of matrix metalloproteinase-9 and increased Akt-Bcl-2 anti-apoptotic signaling
}

\author{
JIUMEI CAO, TIANQI ZHU, LIN LU, LIANG GENG, LINGJIE WANG, \\ QI ZHANG, KE YANG, HAIBO WANG and WEIFENG SHEN
}

\begin{abstract}
Department of Cardiology, Ruijin Hospital, Shanghai Jiaotong University School of Medicine, Shanghai 200025, P.R. China
\end{abstract}
Received January 20, 2011; Accepted March 17, 2011

DOI: 10.3892/ijmm.2011.681

\begin{abstract}
In general, young men have a greater risk than agematched women for many types of cardiovascular diseases, including ischemic heart diseases, such as acute or chronic myocardial infarction (MI)-induced heart failure. The effects of estrogen-replacement therapy in men have not been extensively studied. We evaluated the cardioprotective effects of supplemental estrogen against left anterior descending coronary ligation-induced MI in male C57BL/6J mice. A significantly lower prevalence of cardiac rupture was observed in estrogen-treated mice regardless of castration status. A reduced prevalence of cardiac rupture was associated with decreased activities of matrix metalloproteinase 9 (MMP-9) and increased expression of the anti-apoptotic gene Bcl-2. In vitro studies using $\mathrm{H} 9 \mathrm{C} 2$ cells under simulated ischemia re-oxygenation treatment further support the role of estrogen receptor $\beta$ in estrogen-mediated cardioprotection through the Akt-Bcl-2 signaling pathway.
\end{abstract}

\section{Introduction}

Cardiovascular diseases are the number one cause of death in the USA, and the mortality rate is expected to remain high in the foreseeable future (American Heart Association).

Correspondence to: Professor Weifeng Shen, Department of Cardiology, Ruijin Hospital, Shanghai Jiaotong University School of Medicine, 197 Rui Jin Road II, Shanghai 200025, P.R. China

E-mail: rjshenweifeng@yahoo.com.cn

Abbreviations: MI, myocardial infarction; CVD, cardiovascular disease; MMP, matrix metalloproteinase; SIR, simulated ischemia re-oxygenation; ER, estrogen receptor; FACS, fluorescent activated cell sorting; Cas, castrated;TUNEL, terminal deoxynucleotidyltransferase dUTP nick-end labeling; ECM, extracellular matrix; TNF, tumor necrosis factor; NOS, nitric oxide synthase

Key words: estrogen, cardioprotection, myocardial infarction, MMP-9, apoptosis
Ischemic heart disease and its major complications, such as cardiac rupture caused by acute myocardial infarction (MI) and post-MI heart failure, pose the greatest danger to human life $(1,2)$. It has been known that cardiovascular diseases show dimorphism between the two genders (3), with pre-menopausal women having a lower incidence and lower mortality than men $(4,5)$. However, such an advantage for women becomes far less (or even disappears) after menopause (6). Interestingly, it was shown that the incidence of cardiovascular diseases decreased and prognosis improved if post-menopausal women received estrogen after MI $(7,8)$. This suggested a protective role for the female sex hormone, estrogen. Although this notion has been supported by several animal studies, it has not been proven in clinical trials $(9,10)$. This highlights a more complex picture behind the phenomenon, and merits more thorough research to elucidate the underlying mechanisms.

In the present study, we carried out systematic in vivo and in vitro experiments to study the cardioprotective effects of supplemental estrogen (17 $\beta$-estradiol). Male C57BL/6 mice were chosen as the model to evaluate the effects of estrogen on acute MI-induced cardiac rupture because of a more pronounced remodeling process during the early phase of acute $\mathrm{MI}$ in male rather than in female mice $(11,12)$. Likewise, experiments on the effects of estrogen in male mice may provide new insights into the control of cardiovascular diseases in the male human population. We explored the potential underlying mechanisms by assessing MI-associated changes in the levels of matrix metalloproteinases (MMPs) and in the apoptosis status. In vitro cell culture studies provide further evidence supporting the notion that hypoxia-induced cardiomyocyte apoptosis could be inhibited by supplemental estrogen through the estrogen receptor $\beta(\mathrm{ER} \beta)$-mediated Akt-Bcl-2 signaling pathway.

\section{Materials and methods}

The experimental study was conducted in accordance to the Guide for the Care and Usage of Laboratory Animals published by the US National Institutes of Health (NIH publication number 85-23, revised in 1996). The study protocol 
was approved by the Animal Protection Committee of the Shanghai Jiao Tong University (Shanghai, China).

Animal management and induction of MI. Wild-type male C57BL/6J mice (4 weeks-old, 12-14 g) were housed under identical conditions and fed a standard diet. Mice were randomly subjected to castration (Cas) or sham castration (sham-Cas), for which they were placed supine and the testes removed or left intact via a low-middle abdominal incision. They were then divided into four groups: group 1 , sham-Cas+placebo; group 2, sham-Cas+17 $\beta$-estradiol (SigmaAldrich, St. Louis, MO, USA); group 3, Cas+placebo and group 4, Cas+17 $\beta$-estradiol. Placebo and $17 \beta$-estradiol were administered by subcutaneous pellets inserted on the day of surgery. The dose of $17 \beta$-estradiol was $0.028 \mathrm{mg} /$ day.

Five weeks later, MI was induced by ligation of the left anterior descending coronary artery (LAD) under anesthesia as previously described (16). Briefly, mice were anesthetized with $2.5 \%$ avertin, intubated and ventilated with room air using a positive-pressure respirator (South Natick, MA, USA). A left thoracotomy was performed via the fourth intercostal space. The lungs were retracted to expose the heart, and the pericardium was opened. The LAD was ligated with an 8-0 silk suture near its origin between the pulmonary outflow tract and the edge of the left atrium. Acute MI was considered to have been induced if the anterior wall of the left ventricle turned pale with marked ST-segment elevation. Sham-MI mice were subjected to the same procedure except that the suture around the LAD was not tied. In addition, mice that had not been castrated and who had undergone sham MI served as normal controls. Mice were sacrificed 1, 2, 4, 7 or 14 days after surgery, and the heart was dissected. The left ventricles from half of the mice in each time-point group were sectioned transversely into four slides. One slide was rapidly frozen in liquid nitrogen for protein extraction; the other three slides were embedded in OCT compound (Sakura Finetek, Torrance, CA, USA) for histological examination.

Gelatin zymographic assay. The enzymatic activities of MMP-2 and MMP-9 were determined by gelatin zymography following a previously described method (13). Briefly, the free wall of the left ventricle from the remaining mice in each timepoint group was homogenized in $400 \mu \mathrm{l}$ of an ice-extraction buffer containing cacodylic acid $(10 \mathrm{mM}), \mathrm{NaCl}(0.15 \mathrm{M})$, $\mathrm{ZnCl}(20 \mathrm{mM}), \mathrm{NaN}_{3}(1.5 \mathrm{mM}), 0.01 \%$ Triton X-100 (pH 5.0) and a proteinase inhibitor. The homogenates were centrifuged at $13,600 \mathrm{rpm}$ for $30 \mathrm{~min}$ at $4^{\circ} \mathrm{C}$. The protein concentration in the supernatant was determined using a Bio-Rad protein assay (Bio-Rad, Hercules, CA, USA). Protein $(50 \mu \mathrm{g})$ was diluted in $5 \mathrm{X}$ sample buffer, loaded onto a $10 \%$ zymographic gel (Invitrogen, Carlsbad, CA, USA) and run at $100 \mathrm{~V}$ for $90 \mathrm{~min}$ at room temperature. Gels were incubated in renaturing buffer (2.5\% Triton X-100) for $30 \mathrm{~min}$ and washed in $\mathrm{dH}_{2} \mathrm{O}$ for $10 \mathrm{~min}$, in developing buffer $(50 \mathrm{mM}$ Tris- $\mathrm{HCl}, \mathrm{pH} 8.0,5 \mathrm{mM}$ $\mathrm{CaCl}_{2}, 0.2 \mathrm{M} \mathrm{NaCl}, 0.02 \%$ Brij-35) for $30 \mathrm{~min}$, followed by a fresh developing buffer wash for $16 \mathrm{~h}$ at $37^{\circ} \mathrm{C}$. The developing buffer was discarded and the gels were stained with $0.5 \%$ Coomassie Blue solution (5\% acetic acid, $10 \%$ methanol) for $30 \mathrm{~min}$. The gels were de-stained with $5 \%$ acetic acid and $10 \%$ methanol until sharp bands were visualized. Human MMP-2 or MMP-9 (1 ng) were used as positive controls. The gels were scanned by an imaging densitometer (Bio-Rad, Model GS-670) and digitized using the Molecular Analyst (Bio-Rad) software.

Terminal deoxynucleotidyl transferase (TdT) dUTP nick-end labeling (TUNEL). The TUNEL assay was undertaken following the manufacturer's protocol (TdT Apoptosis Detection kit; Roche, Basel, Switzerland). Frozen left ventricular (LV) tissues were fixed and placed in optimal cutting temperature media (Tissue-Tek, Sakura Finetek), then cut on a cryostat into $4 \mu \mathrm{m}$ sections. Negative controls were serial sections that were not stained with TdT. The TUNEL reaction was incubated for $1 \mathrm{~h}$ at $37^{\circ} \mathrm{C}$ to induce DNA strand breaks. The tissue was blocked with $5 \%$ skimmed milk in phosphate-buffered saline (PBS) with $0.5 \%$ Tween-20 detergent for $30 \mathrm{~min}$. The fluorescent label, fluorescein isothiocyanate (FITC)-conjugated Alexa Fluor 555 streptavidin antibody (Molecular Probes, Eugene, OR, USA), was applied to each section for $30 \mathrm{~min}$, and diluted 1:200 in PBS milk solution to detect ligated biotinylated dNTPs in apoptotic nuclei. Nuclei were then labeled with a blue fluorescent medium 4',6-diamidino-2-phenylindole (DAPI; Vectashield H-1200, Vector Laboratories, Burlingame, CA, USA) and diluted 1:333 in PBS solution. Sections were incubated with DAPI solution for $5 \mathrm{~min}$ and then sequentially rinsed in PBS. Samples were viewed at $\times 20$ magnification with a fluorescent microscope (Olympus IX81F-2; Olympus American, Melville, NY, USA). Images were captured with a camera (Roper Scientific; Cascade Photometrics, Tucson, AZ, USA) and assembled in the Slidebook 4 software (Intelligent Imaging Innovations, Santa Monica, CA, USA). Three transverse sections through the heart were analyzed, of which four sample images were collected per animal. The number of TUNEL-positive cardiomyocyte nuclei in the LV wall was manually counted. Two independent investigators who were blinded to the study protocol carried out the cell counts. Stained cellular debris was eliminated from the counting. Results were calculated using the percentage of positively stained cells in each individual sample.

Cell culture. H9C2 cells were purchased from the American Type Culture Collection (CRL-1446; Manassas, VA, USA). They were routinely maintained in Dulbecco's modified Eagle's medium (DMEM) supplied with $10 \%$ fetal calf serum (FCS) in a humidified atmosphere of $95 \%$ air and $5 \% \mathrm{CO}_{2}$ at $37^{\circ} \mathrm{C}$. Cells were grown at $80 \%$ of confluence prior to exposure to the treatments in the various experiments.

Reverse transcription-polymerase chain reaction (RT-PCR). Total RNA was extracted using an RNeasy Mini kit (Qiagen, Valencia, CA, USA). RNA (1 $\mu \mathrm{g})$ was used to prepare cDNA using an iScript second strand cDNA synthesis kit (Bio-Rad). Synthesized cDNA (100 ng) was used for RT-PCR. The primers were as follows: forward, 5'-GCT CTT GAC AA CCC A-3' and reverse 5'-GCG GCG TT AAC TCG TAG-3' for ER $\alpha$; and forward 5'-GGCTGA GGA AG CAC CTG TC-3' and reverse 5'-GCG GCG TTG AAC TCG TAG-3' for ER $\beta$. Transcripts were separated by agarose gel electrophoresis.

Fluorescence-activated cell sorting (FACS) analyses. In this experiment, H9C2 cells were serum-starved for $24 \mathrm{~h}$ for 
cell-cycle synchronization and then divided into three groups treated in triplicate. The first group was incubated in normoxic conditions (NSIR); the second group was treated with placebo (P) simultaneously while being subjected to $16 \mathrm{~h}$ of hypoxia followed by $2 \mathrm{~h}$ of re-oxygenation treatment (SIR+P); and the third group was treated with $17 \beta$-estradiol $(200 \mathrm{nM})$ simultaneously while being subjected to $16 \mathrm{~h}$ of hypoxia and $2 \mathrm{~h}$ of re-oxygenation $(\mathrm{SIR}+\mathrm{E})$. The cell cycle phases were determined by flow cytometry in propidium iodide (PI)-stained cells. In brief, cells were digested with trypsin-ethylene-diaminetetra-acetic acid (EDTA). Cells $\left(2 \times 10^{6}\right)$ were collected by low-speed centrifugation and washed with cold PBS. Cells were collected again by centrifugation, fixed with $70 \%$ ethanol at room temperature for $\geq 30 \mathrm{~min}$, then stored at $-20^{\circ} \mathrm{C}$ overnight. After washing twice, cells were stained with $50 \mu \mathrm{g} / \mathrm{ml}$ of PI, and $10 \mathrm{mg} / \mathrm{ml}$ of RNase A (Bachem, Torrance, CA, USA) was added $30 \mathrm{~min}$ before flow cytometry analyses. Red fluorescence was measured with a FACScan (Becton-Dickinson, San Jose, CA, USA). DNA content and cell-cycle profiles were analyzed to determine the fractions of the population in each phase of the cell cycle (apoptosis, G0/G1, S, G2/M).

Western blot analysis. To evaluate the $\mathrm{Bcl}-2$ protein level in the infarct zones, the LV wall was homogenized in RIPA buffer containing $50 \mathrm{mM}$ Tris- $\mathrm{HCl} \mathrm{pH} 7.4,1 \% \mathrm{NP}-40,0.25 \%$ Na-deoxycholate, $150 \mathrm{mM} \mathrm{NaCl}, 1 \mathrm{mM}$ EDTA, $1 \mathrm{mM}$ phenylmethanesulphonylfluoride (PMSF), $1 \mu \mathrm{g} / \mathrm{ml}$ each of aprotinin, leupeptin, and pepstatin, $1 \mathrm{mM} \mathrm{Na} \mathrm{VO}_{4}$, and $1 \mathrm{mM} \mathrm{NaF}$, supplemented with complete EDTA-free proteinase inhibitor tablets (Roche). Lysates were mixed well and centrifuged at $15,000 \times \mathrm{g}$ for $30 \mathrm{~min}$ at $4^{\circ} \mathrm{C}$. The supernatant was collected for further analyses. The Bradford assay (Bio-Rad) was used to determine protein concentrations.

In the cell treatment experiment, $\mathrm{H} 9 \mathrm{C} 2$ cells were divided into three groups. Group 1 was subjected to SIR, but without $17 \beta$-estradiol treatment; group 2 was treated with $17 \beta$-estradiol (200 nM) simultaneously while being subjected to SIR; and group 3 was treated with $17 \beta$-estradiol $(200 \mathrm{nM})$ along with the ER inhibitor, ICI $182,780(1 \mu \mathrm{M})$, simultaneously while being subjected to SIR. At each time-point, cells were washed twice with ice-cold PBS and lysed in RIPA buffer [50 mM of Tris- $\mathrm{HCl}, \mathrm{pH} 7.5,150 \mathrm{mM}$ of $\mathrm{NaCl}, 1 \% \mathrm{NP}-40,0.5 \%$ sodium deoxycholate and $0.1 \%$ sodium dodecyl sulfate (SDS)] supplemented with a protease inhibitor and phosphatase inhibitor cocktail (Sigma-Aldrich). The protein concentration was determined using the Bio-Rad protein assay.

Total protein $(10 \mu \mathrm{g})$ were separated by SDS-polyacrylamide gel electrophoresis (SDS-PAGE) with Tris-HCl gel (Ready Gel, Bio-Rad), followed by transfer to polyvinylidene difluoride membranes (Immobilon-P, Millipore, Bedford, MA, USA). Membranes were incubated in blocking buffer (5\% non-fat milk in T-PBS) for $1 \mathrm{~h}$ and immunoblotted with primary antibodies diluted in 5\% bovine serum albumin (BSA; Sigma-Aldrich). Membranes were probed with horseradish peroxidase (HRP)conjugated secondary antibody (Jackson ImmunoResearch Laboratories, West Grove, PA, USA). Western blots were visualized by the enhanced chemiluminescence technique (Amersham ECL Western Blotting Detection Reagents, GE Healthcare, Piscataway, NJ, USA). The primary antibodies used were anti-ACTB, anti-GAPDH, anti-Akt, anti-phospho

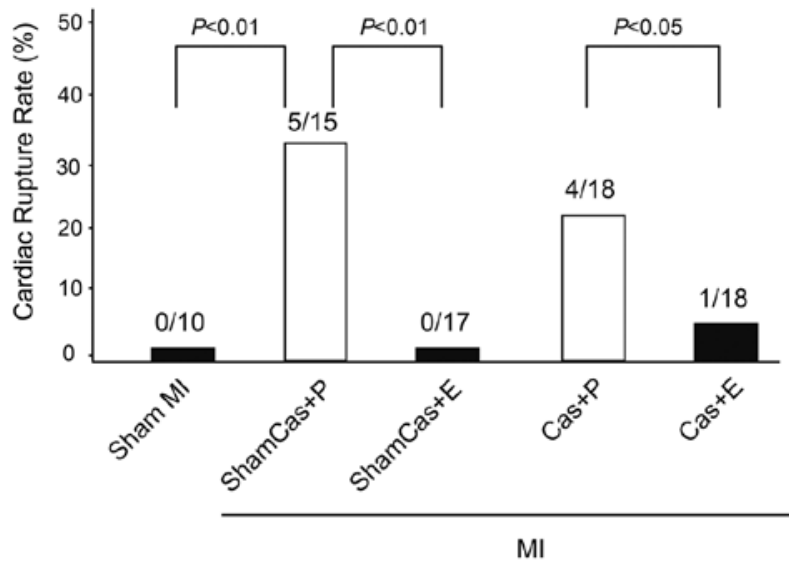

Figure 1. Supplemental estrogen reduced the prevalence of cardiac rupture during the first week of myocardial infarction (MI) in mice. The prevalence of rupture was counted only in mice assigned to the 7-day groups. Mice receiving supplemental $17 \beta$-estradiol (E) treatment had a significantly lower prevalence of cardiac rupture than those treated with placebo $(\mathrm{P})$. Cas, castrated.

Akt and anti-Bcl-2 (all from Cell Signaling Technology, Danvers, MA, USA).

Statistical analyses. The prevalence of cardiac rupture was compared using $\chi^{2}$ tests. Protein activities were compared using the Student's t-test. $\mathrm{P}<0.05$ were regarded as a statistically significant difference.

\section{Results}

Prevalence of cardiac rupture. All cardiac ruptures occurred within 1 week after MI induction (Fig. 1). The prevalence of cardiac rupture was counted only in mice assigned to the 7-day groups. No mouse within the sham-MI group (10 mice) died from cardiac rupture. Five mice $(33 \%)$ in the sham-Cas+placebo group died from cardiac rupture after MI. There was no cardiac rupture-related death in the mice receiving treatment with sham-Cas $+17 \beta$-estradiol. Castration alone modestly reduced the prevalence of cardiac rupture in male mice: 4 mice $(22 \%)$ died from cardiac rupture in the Cas+placebo group. Mice receiving supplemental $17 \beta$-estradiol treatment had a significantly lower prevalence of cardiac rupture than those treated with placebo, regardless of the castration status.

Effect of estrogen on MMP activities. After MI, MMP-9 activity was increased as early as day 1 and reached a maximum by day 2 , followed by a gradual loss of activity between day 4 and 14 (Fig. 2A). MMP-2 activity remained latent on day 1 and day 2 , but started to show increased activity on day 4 , with maximum activity recorded on day 7 (Fig. 2B). For mice receiving castration and placebo, the activity of MMP-9 was slightly lower when compared to mice receiving placebo but sham castration (Fig. 2A and C). Regardless of the castration status, however, mice receiving supplemental estrogen always had significantly lower MMP-9 activities than those receiving placebo at each time-point (Fig. 2A and C). No significant difference in the MMP-2 activity was seen in mice after MI induction (Fig. 2B). 
A

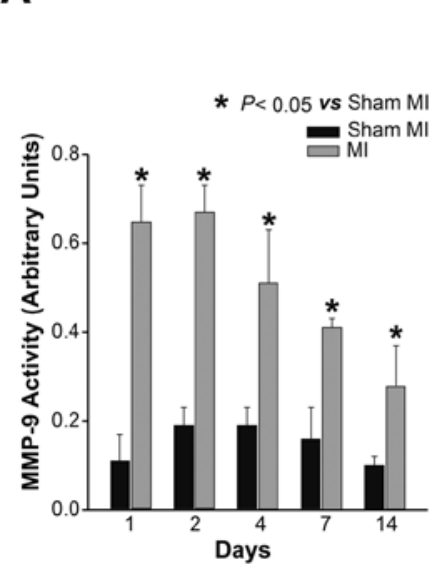

B

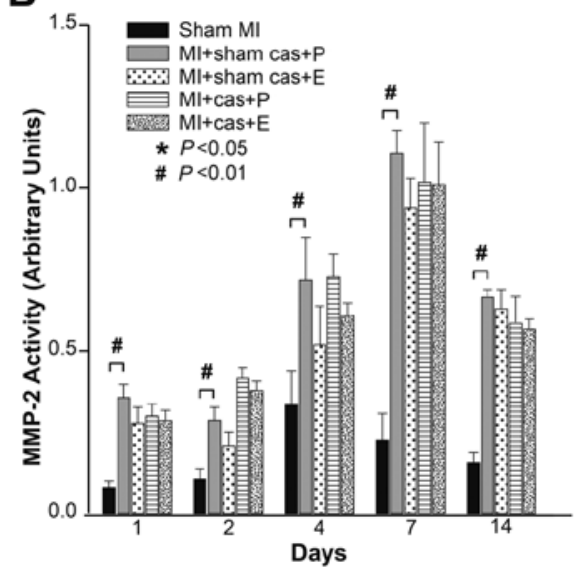

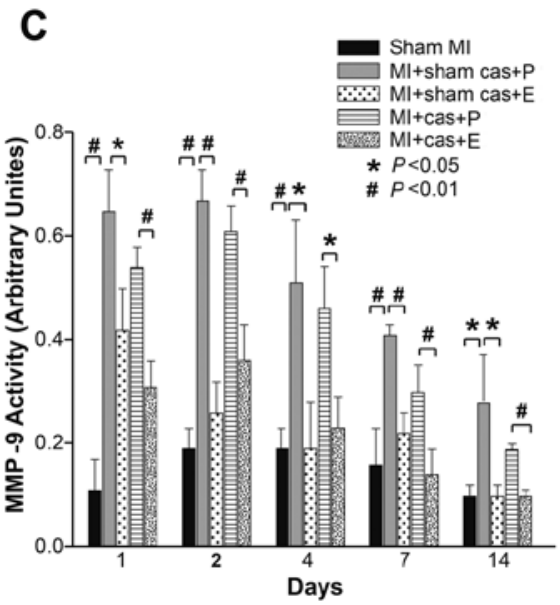

Figure 2. Time-course of MMP-9 and MMP-2 activation in the left ventricle of mice after myocardial infarction (MI). (A) After MI, MMP-9 activity increased as early as day 1 and reached a maximum by 2 days, then gradually decreased $(n=10,10,9,9$ and 10, for the 1,2, 4, 7 and 14-day time-points, respectively, in both groups). (B) MMP-2 activity remained latent on day 1 and day 2, but started to show increased activity on day 4, with maximum activity recorded on day 7 after MI ( $\mathrm{n}=7$ in each group). MMP-2 activity increased in the MI-induced group compared with the sham-MI group. No significant difference in the MMP-2 activity was observed in mice after MI induction. (C) Mice receiving supplemental estrogen (E) had significantly lower MMP-9 activities than those receiving placebo $(\mathrm{P})$ at each time-point ( $\mathrm{n}=7$ in each group). cas, castrated.

A

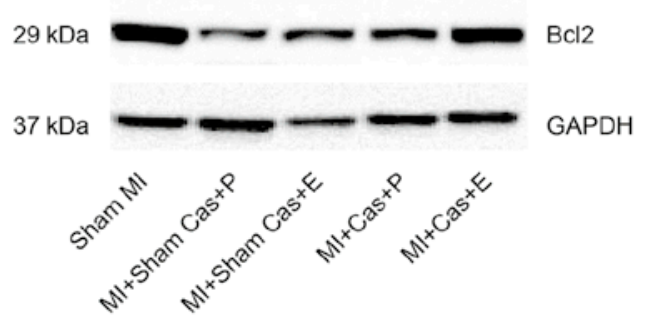

C

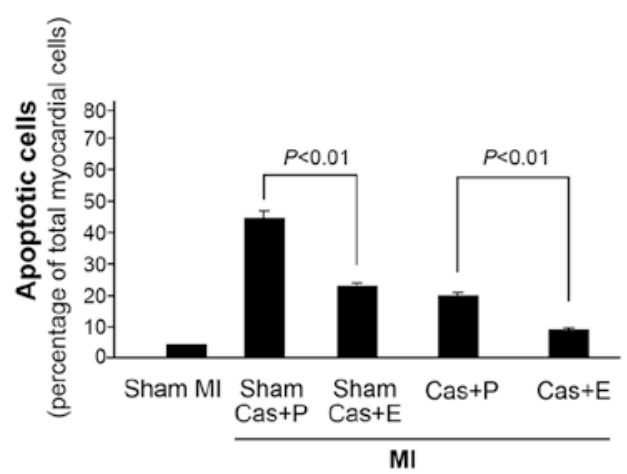

B

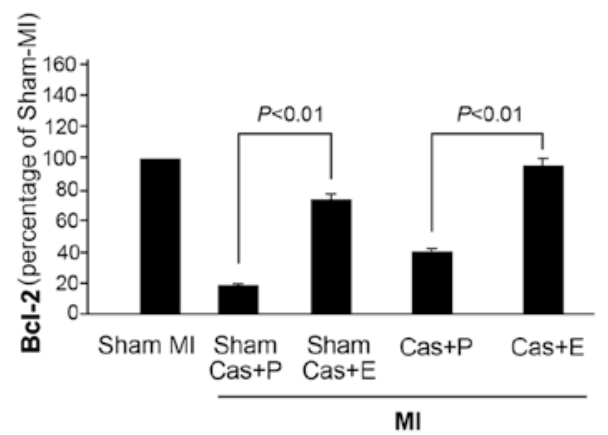

D

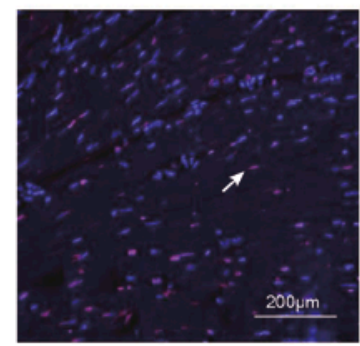

$\mathrm{Ml}+$ Sham Cas $+\mathrm{P}$
Tunel Positive Nuclei in mice heart

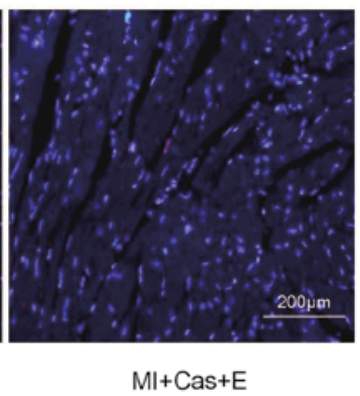

Figure 3. Effect of estrogen (E) on myocardial levels of Bcl-2 and on apoptosis as determined by the TUNEL assay. (A) Tissue lysates from the left ventricular infarct zones on day 7 were immunoblotted with antibodies specific for Bcl-2. (B) Densitometric analyses of Bcl-2 and GAPDH levels (three independent experiments were performed). (C) OCT-embedded sections of left ventricular slides on day 7 were examined by the TUNEL assay to detect apoptosis. Immunolabeled nuclei of myocytes were determined by random counting of 10 fields per section. Each bar represents the mean \pm SD of three hearts. (D) Representative staining pattern. Arrows indicate TUNEL-positive nuclei (stained red). Cas, castrated; MI, myocardial infarction; P, placebo. Magnification $\mathrm{x} 200$.

Cardiomyocyte apoptosis. Cardiomyocyte apoptosis in infarct or peri-infarct zones was studied by measuring the expression of the anti-apoptotic protein, Bcl-2 (Fig. 3A and B), and by using the TUNEL assay (Fig. 3C and D). Sham-MI control mice had significantly higher expression of Bcl-2 compared with MI-induced mice. Among the MI-induced mice, the expression level of Bcl-2 went from the highest to the lowest in the following order: Cas $+17 \beta$-estradiol $>$ sham-Cas $+17 \beta$ estradiol $>$ Cas+placebo $>$ sham-Cas+placebo. The data suggest an inhibitory effect of estrogen on acute MI-induced cardiomyocyte apoptosis. The TUNEL assay revealed that mice receiving estrogen treatment (MI+Cas+E) had significantly 
A
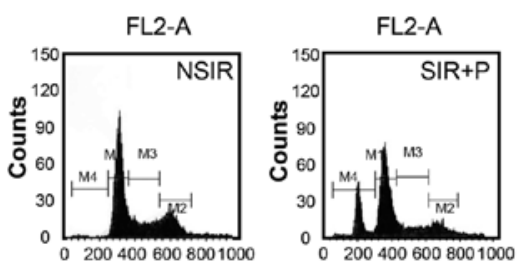

C

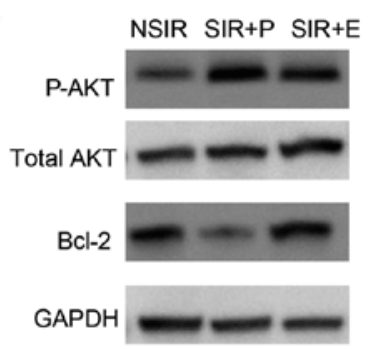

E

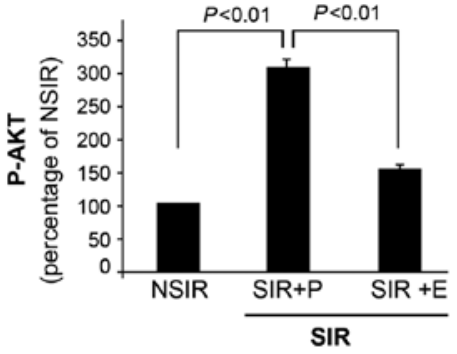

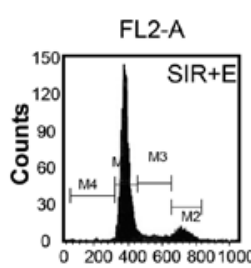

D

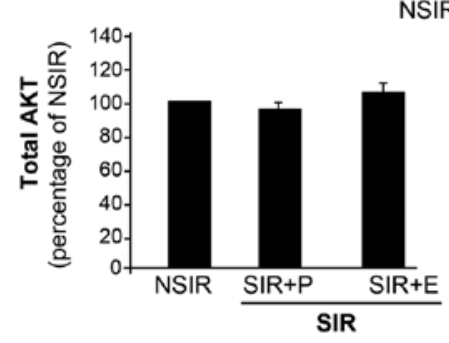

$\mathbf{F}$

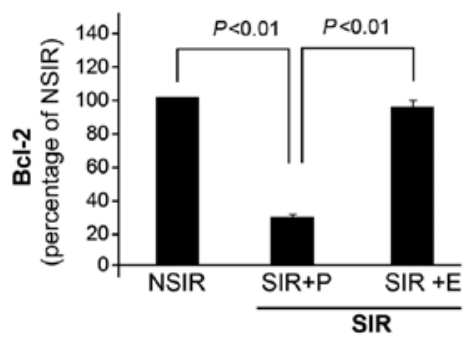

Figure 4. The Akt-Bcl-2 anti-apoptotic signaling pathway is enhanced in 17ß-estradiol (E)-treated H9C2 cells. (A) FACS assay of three groups of H9C2 cells: normoxic (NSIR), simulated ischemia and re-oxygenation (SIR) +placebo and SIR+E. (B) H9C2 cells with SIR treated by supplemental E showed very little apoptosis (1\%), similar to the cells incubated under normoxic conditions. (C) Western blot analyses of Bcl-2, total Akt, P-Akt and GAPDH from three groups of H9C2 cells. (D-F) Densitometric analyses of total Akt, P-Akt and Bcl-2 levels (three independent experiments were performed).

fewer TUNEL-positive cells than those receiving placebo $(\mathrm{MI}+\mathrm{Cas}+\mathrm{P}, \mathrm{P}<0.01)$.

We therefore, observed a tight correlation between the expression levels of MMP-9 and Bcl-2 and the prevalence of cardiac rupture of each group of mice. This indicates that estrogen may protect MI-induced male mice from cardiac rupture by modulating degradation of the extracellular matrix $(\mathrm{ECM})$ and the apoptosis signaling pathways.

The Akt-Bcl-2 anti-apoptotic signaling pathway is enhanced in estrogen-treated cells. To further investigate the role of apoptosis in estrogen-mediated cardioprotection, we examined the responses of $\mathrm{H} 9 \mathrm{C} 2$ myocardial cells to simulated ischemia and re-oxygenation (SIR) treatment. Such hypoxiare-oxygenation treatment mimics the physiological stress induced by myocardial infarction.

We performed FACS analysis in three groups of cells: normoxic (NSIR), SIR+P and SIR+E (Fig. 4A). Cells treated by supplemental $17 \beta$-estradiol $(200 \mathrm{nM})$ and then with $16 \mathrm{~h}$ of hypoxia and $2 \mathrm{~h}$ of re-oxygenation showed $1 \%$ apoptosis (Fig. 4B), similarly to the cells incubated under normoxic conditions (NSIR, Fig. 4B). In striking contrast, a significantly large proportion of cells underwent apoptosis when treated by SIR. Such differences were correlated with the protein levels of phospho-Akt and Bcl-2 as shown by Western blotting (Fig. 4C).

It has been reported that supplemental estrogen treatment protects $\mathrm{H} 9 \mathrm{C} 2$ cells from apoptosis induced by $\mathrm{H}_{2} \mathrm{O}_{2}$-induced oxidative stress through regulation of the Akt protein via the glutathione/glutaredoxin-dependent redox (14). In estrogen-, but not ICI 182,780-treated cells up-regulation of Akt-Bcl-2 signaling was observed (Fig. 5D). Minimal expression of ER $\alpha$, but abundant expression of ER $\beta$ (Fig. 5A) was observed in $\mathrm{H} 9 \mathrm{C} 2$ cells. The data suggest that $\mathrm{ER} \beta$ is (at least in part) involved in the estrogen-mediated cardioprotective effects through the Akt-Bcl-2 signaling pathway.

\section{Discussion}

Sex hormones (i.e., estrogen, progesterone and androgens) and their receptors (ERs, PRs and ARs, respectively) have been favored as the candidates to mediate sex-specific effects in the cardiovascular system. Among the three types of sex hormones, estrogen has received the most attention.

The cardioprotective effects of estrogen have been observed in post-menopausal women receiving estrogen replacement therapy $(7,8)$. There is an abundance of studies supporting the cardioprotective effects of estrogen after ischemic injuries, such as MI (14-22). Most of these studies in mice have been conducted in female animals whose ovaries have been surgically removed (ovariectomized mice). Whether estrogen exerts similar cardioprotective effects in males is not known.

The present study aimed to address whether estrogen exerts a cardioprotective effect in males. Our in vivo data demonstrated that supplemental estrogen treatment in male mice reduces the prevalence of cardiac rupture during the 
A

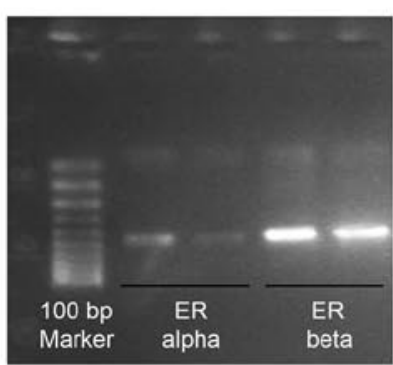

B

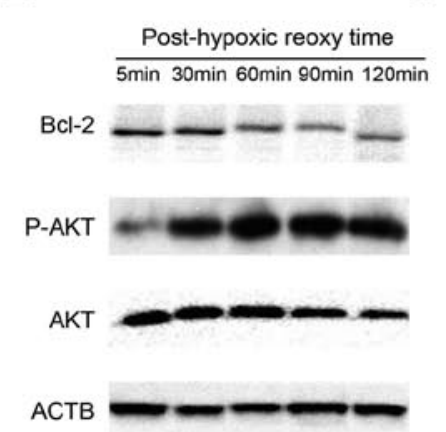

C

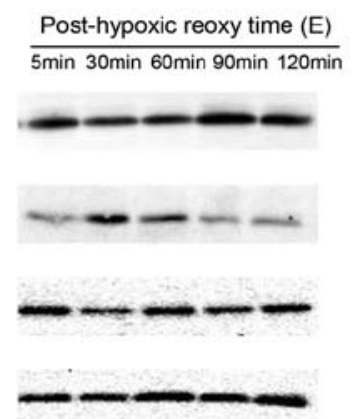

D

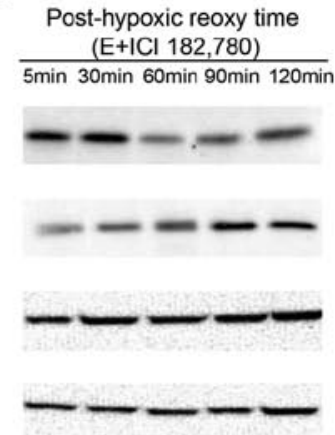

Figure 5. Effects of estrogen (E) and ICI 182,780 on H9C2 cells with respect to total Akt, P-Akt and Bcl-2. (A) Determination of estrogen-receptor expression of H9C2 cells by RT-PCR. (B) Time-course of Akt phosphorylation and Bcl-2 expression in H9C2 cells under SIR. Cells were subjected to 16 h of hypoxia followed by 120 min of re-oxygenation. (C) and (D) H9C2 cells were treated with $200 \mathrm{nM} 17 \beta$-estradiol (E) in the absence (C) or presence (D) of $1 \mu \mathrm{M}$ ICI 182,780 and then the cells were subjected to $16 \mathrm{~h}$ of hypoxia followed by $120 \mathrm{~min}$ of re-oxygenation.

acute phase of MI. This result contradicts findings by Cavasin et al (15). In their studies, short-term (acute) and long-term (chronic) cardiac function in MI-induced male mice treated with estrogen and female mice treated with testosterone was evaluated. Opposing effects were observed for chronic cardiac remodeling and function, with favorable (protective) effects exerted by estrogen and detrimental effects exerted by testosterone (15). During the acute phase of MI, however, estrogen appeared to offer no or little protection against acute MI-induced cardiac rupture $(15,23)$. Our data indicate that castration alone could reduce the prevalence of cardiac rupture in male mice: $22 \%$ of castrated mice died from cardiac rupture compared with $33 \%$ of mice receiving sham castration. This result is consistent with the studies of Cavasin et al, but the difference in our study was far less conspicuous. Cavasin et al reported 9 cardiac rupture deaths in the sham-Cas group but none in the Cas group (15). The most pronounced difference, however, between the two studies is in the mice receiving estrogen treatment. We observed a significantly lower prevalence of cardiac rupture in estrogen-treated mice than in placebo-treated mice $(\mathrm{P}<0.01$ for sham-Cas mice and $\mathrm{P}<0.05$ for Cas mice). In contrast, there was no significant difference observed in the studies of Cavasin et al $(15,23)$. The underlying reason for such a disparity may be attributable to multiple factors. For example, different doses of $17 \beta$-estradiol were used in the two studies ( $28 \mu \mathrm{g} /$ day in our study vs. $23 \mu \mathrm{g} /$ day in their study). In addition, the duration of estrogen treatment between the time of castration and MI induction was different between the two studies (5 weeks in our study vs. 6 weeks in their study).

Degradation of the ECM by MMPs is known to be involved in post-MI healing and remodeling. Knockout mice targeting the MMP-9 gene (the primary MMP protein functioning in post-MI cardiac remodeling) were reported to have a reduced prevalence of cardiac rupture and attenuated LV remodeling compared to control mice $(24,25)$. In addition, a temporal change in the expression of MMP-9 and MMP-2 after MI has been found (13). In the current study, we observed similar changes in the temporal expression of MMP-9 and MMP-2 proteins after MI induction in mice receiving shamCas+placebo treatment. With estrogen treatment, however, we observed a significant reduction in MMP-9 expression $(\mathrm{P}<0.05$ or 0.01 ), regardless of castration status. Such a reduction was not observed in the MMP-2 protein.

Apoptosis of cardiomyocytes in infarct or peri-infarct zones was noted in the current study. We saw a significant difference in the expression of the anti-apoptotic protein $\mathrm{Bcl}-2$ between treated and control mice. The highest amount of Bcl-2 was observed in mice receiving MI+Cas+estrogen treatment, followed by the groups treated with MI+sham-Cas+estrogen, $\mathrm{MI}+\mathrm{Cas}+$ placebo and MI+sham-Cas+placebo, respectively. The TUNEL assay confirmed increased apoptosis in placebotreated mice.

The underlying mechanism for estrogen-induced inhibition of apoptosis after MI is incompletely understood. Several authors have recently suggested such inhibition may be governed by an ER-mediated, Akt-dependent signaling pathway $(14,16,21)$. Overall, these studies have helped to establish a pivotal role for the Akt gene in estrogen-induced inhibition of apoptosis. However, we do not know which ER isoform (ER $\alpha$ or $\mathrm{ER} \beta$ ) plays the major role. In the current study, we studied the protective effects of estrogen on hypoxia-induced apoptosis using H9C2 cells, which minimally express ER $\alpha$. Using the same cell line, Urata et al revealed that $17 \beta$-estradiol protects against apoptosis induced by $\mathrm{H}_{2} \mathrm{O}_{2}$-induced oxidative stress through the glutathione/glutaredoxin-dependent redox regulation of the Akt protein (14). Our study has shown that, after $16 \mathrm{~h}$ of estrogen treatment, the activity of the pro-apoptotic Akt (P-Akt) began to decrease, while the expression of the anti-apoptotic Bcl-2 began to increase. Cell-cycle analyses indicated that hypoxia-induced apoptosis was efficiently inhibited by supplemental $17 \beta$-estradiol. Our data, along with results reported by other research teams $(14,17,21,22)$, substantiate the concept that ER $\beta$ is (at least in part) involved in the estrogen-mediated cardioprotection.

In addition to the mechanisms discussed above, other potential mechanisms may contribute to the cardioprotective effects of estrogen. For example, it has been reported that estrogen exerts cardioprotective effects by modulating the cardiac expression of tumor necrosis factor- $\alpha$ (TNF $\alpha$ ) and its receptor (19). In addition, nitric oxide synthase (NOS) has also been shown to mediate estrogen-induced cardioprotection $(18,22)$. Therefore, the entire mechanism may be far beyond our current state of knowledge. It has also been shown that the 
androgen, testosterone, exerts opposite effects from estrogen, causing rupture and degradation of cardiac function (23). Hence, the exact functional relationship between estrogen and androgen in the cardiovascular system must be further investigated.

\section{Acknowledgements}

We thank Professor Shengfang Ge from Shanghai Jiaotong University for his helpful discussions on this manuscript. This study was supported by the National Natural Science Foundation of China $(30871084,81070240)$ to W. S.

\section{References}

1. Nishihama K, Yamada Y, Matsuo H, Segawa T, Watanabe S, Kato K, Yajima K, Hibino T, Yokoi K, Ichihara S, Metoki N, Yoshida H, Satoh K and Nozawa Y: Association of gene polymorphisms with myocardial infarction in individuals with or without conventional coronary risk factors. Int J Mol Med 19: 129-141, 2007.

2. Melle C, Camacho JA, Surber R, Betge S, Von Eggeling F and Zimmer T: Region-specific alterations of global protein expression in the remodelled rat myocardium. Int J Mol Med 18: $1207-1215,2006$.

3. Regitz-Zagrosek V: Therapeutic implications of the genderspecific aspects of cardiovascular disease. Nat Rev Drug Discov 5: 425-438, 2006.

4. Brett KM and Madans JH: Long-term survival after coronary heart disease.Comparisons between men and women in a national sample. Ann Epidemiol 5: 25-32, 1995.

5. Adams KF Jr, Sueta CA, Gheorghiade M, O'Connor CM, Schwartz TA, Koch GG, Uretsky B, Swedberg K, McKenna W, Soler-Soler J and Califf RM: Gender differences in survival in advanced heart failure. Insights from the FIRST study. Circulation 99: 1816-1821, 1999.

6. Barrett-Connor E: Postmenopausal estrogen and heart disease. Atherosclerosis 118 (Suppl): S7-S10, 1995.

7. Shlipak MG, Angeja BG, Go AS, Frederick PD, Canto JG and Grady D: Hormone therapy and in-hospital survival after myocardial infarction in postmenopausal women. Circulation 104: 2300-2304, 2001

8. Lindenfeld J, Ghali JK, Krause-Steinrauf HJ, Khan S, Adams K, Goldman S,Peberdy MA, Yancy C, Thaneemit-Chen S, Larsen RL, Young J, Lowes B, Rosenberg YD; BEST Investigators: Hormone replacement therapy is associated with improved survival in women with advanced heart failure. J Am Coll Cardiol 42: 1238-1245, 2003.

9. Hulley S, Grady D, Bush T, Furberg C, Herrington D, Riggs B and Vittinghoff E: Randomized trial of estrogen plus progestin for secondary prevention of coronary heart disease in postmenopausal women. Heart and Estrogen/progestin Replacement Study (HERS) Research Group. JAMA 280: 605-613, 1998.

10. Rossouw JE, Anderson GL, Prentice RL, LaCroix AZ, Kooperberg C, Stefanick ML,Jackson RD, Beresford SA, Howard BV, Johnson KC, Kotchen JM, Ockene J; Writing Group for the Women's Health Initiative Investigators: Risks and benefits of estrogen plus progestin in healthy postmenopausal women: principal results from the Women's Health Initiative randomized controlled trial. JAMA 288: 321-333, 2002.

11. Cavasin MA, Tao Z, Menon S and Yang XP: Gender differences in cardiac function during early remodeling after acute myocardial infarction in mice. Life Sci 75: 2181-2192, 2004.

12. Gao XM, Xu Q, Kiriazis H, Dart AM and Du XJ: Mouse model of post-infarct ventricular rupture: time course, strainand gender-dependency, tensile strength, and histopathology. Cardiovasc Res 65: 469-477, 2005.
13. Tao ZY, Cavasin MA, Yang F, Liu YH and Yang XP: Temporal changes in matrix metalloproteinase expression and inflammatory response associated with cardiac rupture after myocardial infarction in mice. Life Sci 74: 1561-1572, 2004.

14. Urata Y, Ihara Y, Murata H, Goto S, Koji T, Yodoi J, Inoue S and Kondo T: 17Beta-estradiol protects against oxidative stress-induced cell death through the glutathione/glutaredoxindependent redox regulation of Akt in myocardiac H9c2 cells. J Biol Chem 281: 13092-13102, 2006.

15. Cavasin MA, Sankey SS, Yu AL, Menon S and Yang XP: Estrogen and testosterone have opposing effects on chronic cardiac remodeling and function in mice with myocardial infarction. Am J Physiol Heart Circ Physiol 284: H1560-H1569, 2003.

16. Patten RD, Pourati I, Aronovitz MJ, Baur J, Celestin F, Chen X, Michael A, Haq S, Nuedling S, Grohe C, Force T, Mendelsohn ME and Karas RH: 17beta-estradiol reduces cardiomyocyte apoptosis in vivo and in vitro via activation of phospho-inositide-3 kinase/Akt signaling. Circ Res 95: 692-699, 2004.

17. Korte T, Fuchs M, Arkudas A, Geertz S, Meyer R, Gardiwal A, Klein G, Niehaus M, Krust A, Chambon P, Drexler H, Fink K and Grohé C: Female mice lacking estrogen receptor beta display prolonged ventricular repolarization and reduced ventricular automaticity after myocardial infarction. Circulation 111: 2282-2290, 2005.

18. Iwakura A, Shastry S, Luedemann C, Hamada H, Kawamoto A, Kishore R, Zhu Y, Qin G, Silver M, Thorne T, Eaton L, Masuda H, Asahara T and Losordo DW: Estradiol enhances recovery after myocardial infarction by augmenting incorporation of bone marrow-derived endothelial progenitor cells into sites of ischemia-induced neovascularization via endothelial nitric oxide synthase-mediated activation of matrix metalloproteinase-9. Circulation 113: 1605-1614, 2006.

19. Xu Y, Arenas IA, Armstrong SJ, Plahta WC, Xu H and Davidge ST: Estrogen improves cardiac recovery after ischemia/ reperfusion by decreasing tumor necrosis factor-alpha. Cardiovasc Res 69: 836-844, 2006.

20. Zhan E, Keimig T, Xu J, Peterson E, Ding J, Wang F and Yang XP: Dose-dependent cardiac effect of oestrogen replacement in mice post-myocardial infarction. Exp Physiol 93: 982-993, 2008.

21. Wang M, Wang Y, Weil B, Abarbanell A, Herrmann J, Tan J, Kelly $M$ and Meldrum DR: Estrogen receptor beta mediates increased activation of PI3K/Akt signaling and improved myocardial function in female hearts following acute ischemia. Am J Physiol Regul Integr Comp Physiol 296: R972-R978, 2009.

22. Lin J, Steenbergen C, Murphy E and Sun J: Estrogen receptorbeta activation results in S-nitrosylation of proteins involved in cardioprotection. Circulation 120: 245-254, 2009.

23. Cavasin MA, Tao ZY, Yu AL and Yang XP: Testosterone enhances early cardiac remodeling after myocardial infarction, causing rupture and degrading cardiac function. Am J Physiol Heart Circ Physiol 290: H2043-H2050, 2006.

24. Heymans S, Luttun A, Nuyens D, Theilmeier G, Creemers E, Moons L, Dyspersin GD, Cleutjens JP, Shipley M, Angellilo A, Levi M, Nübe O, Baker A, Keshet E, Lupu F, Herbert JM, Smits JF, Shapiro SD, Baes M, Borgers M, Collen D, Daemen MJ and Carmeliet P: Inhibition of plasminogen activators or matrix metalloproteinases prevents cardiac rupture but impairs therapeutic angiogenesis and causes cardiac failure. Nat Med 5: 1135-1142, 1999.

25. Ducharme A, Frantz S, Aikawa M, Rabkin E, Lindsey M, Rohde LE, Schoen FJ,Kelly RA, Werb Z, Libby P and Lee RT: Targeted deletion of matrix metalloproteinase- 9 attenuates left ventricular enlargement and collagen accumulation after experimental myocardial infarction. J Clin Invest 106: 55-62, 2000. 